\title{
Correction to: Influence of body weight unloading on human gait characteristics: a systematic review
}

Salil Apte ${ }^{1}$, Michiel Plooij ${ }^{1,2}$ and Heike Vallery ${ }^{3^{*}}$

\section{Correction}

The original article [1] contained a major error whereby Fig. 1 mistakenly displayed a duplicate of Fig. 5. The correct version of Fig. 1 has now been restored and can be viewed ahead.

Furthermore, this error was mistakenly introduced by the production team that handled this article and as such, was not the fault of the authors.

\section{Author details}

'Mechanical, Maritime and Materials Engineering (3mE), TU Delft, Mekelweg

2, 2628 Delft, CD, Netherlands. ${ }^{2}$ Motekforce Link, Hogehilweg 18-C, 1101

Amsterdam, CD, Netherlands. ${ }^{3}$ Mechanical, Maritime and Materials

Engineering (3mE), TU Delft, Mekelweg 2, 2628 Delft, CD, Netherlands.

Received: 26 June 2018 Accepted: 11 July 2018

Published online: 08 August 2018

\section{Reference}

1. Apte S, Plooij M, Vallery H. Influence of body weight unloading on human gait characteristics: a systematic review. J Neuroeng Rehabil. 2018;15:53. https://doi.org/10.1186/s12984-018-0380-0.

* Correspondence: h.vallery@tudelft.nl

${ }^{3}$ Mechanical, Maritime and Materials Engineering (3mE), TU Delft, Mekelweg 2, 2628 Delft, CD, Netherlands

Full list of author information is available at the end of the article

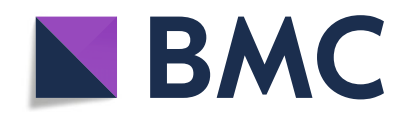

(c) The Author(s). 2018 Open Access This article is distributed under the terms of the Creative Commons Attribution 4.0 International License (http://creativecommons.org/licenses/by/4.0/), which permits unrestricted use, distribution, and reproduction in any medium, provided you give appropriate credit to the original author(s) and the source, provide a link to the Creative Commons license, and indicate if changes were made. The Creative Commons Public Domain Dedication waiver (http://creativecommons.org/publicdomain/zero/1.0/) applies to the data made available in this article, unless otherwise stated. 


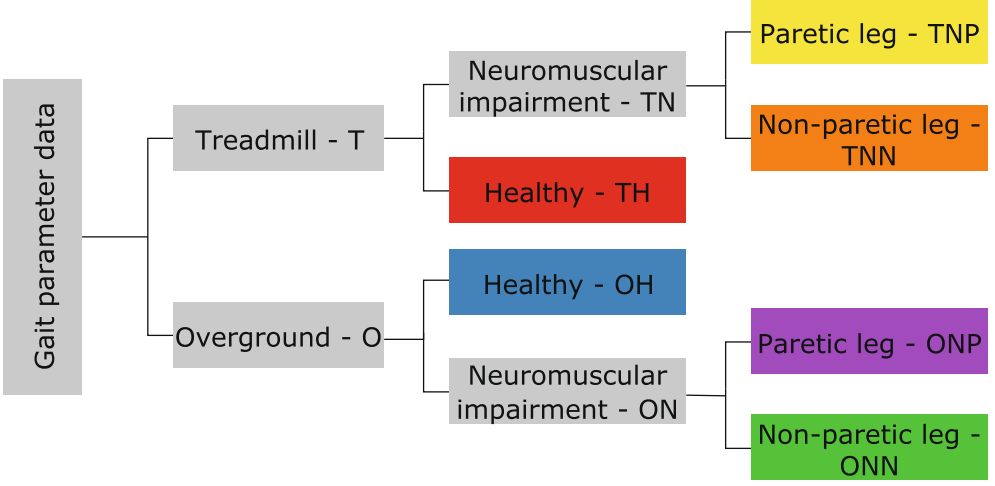

Fig. 1 Flowchart for classification of studies into six categories which are indicated in colour. Similar colour scheme is followed in Figs. 3, 4, 5, and 6 in the results section 